- a top priority for the then-new administration of US President Barack Obama. It would bring together all the necessary expertise, from basic and applied research to engineering and early product development.

Four years later, there is justified, if cautious, optimism about the outcome of Chu's experiment. Viewed purely as research projects, most of the hubs seem to be doing well. In the next few months, the Joint Center for Artificial Photosynthesis, headquartered at the California Institute of Technology in Pasadena, hopes to demonstrate a first-generation prototype of an 'artificial leaf' - a cheap, robust and highly efficient system able to make liquid fuels out of sunlight, air and water (see page 22). The Joint Center for Energy Storage Research, headquartered at the DOE's Argonne National Laboratory near Chicago in Illinois, is likewise making good progress towards its goal: devices that can store much more electricity in much less space than the current champions, lithium-ion batteries (see Nature 507, 26-28; 2014).

Only one of the five hubs has fallen by the wayside. The Energy Efficient Buildings hub, headquartered in Philadelphia, Pennsylvania, was eventually judged to be too diffuse in its goals for DOE purposes, and too oriented towards trying to get people to use currently available technology. But it still exists. In April it took a new name - the Consortium for Building Energy Innovation - and relaunched itself as an independent research and demonstration centre.

There are also grounds for optimism about the hubs' larger purpose of transforming the DOE research culture - although in this case, the progress is less clear-cut. In some ways the agency is as bureaucratic as ever. And talk of change within the department has provoked its share of resistance from individuals who feel that their programmes are threatened.

Nevertheless, there is considerable excitement in the DOE - a sense of new opportunities, new ventures, new people. The hubs are responsible for some of that feeling, as are innovations such as the Advanced Research Projects Agency - Energy (ARPA-E), established in 2009 to fund speculative, high-risk, high-reward investigations, and a network of Energy Frontier Research Centers, launched the same year to promote cutting-edge basic research.

But at least as important is the sense that the people at the top understand and support reform. Chu's initiatives have been continued by

his successor, physicist Ernest Moniz — who last year told Congress that the hubs would be a good model for reforming the DOE's network of 17 national laboratories. Last month, Moniz appointed a panel to review the national labs, with a report due early next year.

Obama's administration has been supportive. In both his 2013 and 2014 State of the Union addresses, Obama called for a US\$1-billion National Network for Manufacturing Innovation. An interagency

"There is considerable excitement in the Department of Energy - a sense of new opportunities, new ventures, new people." programme modelled in part on the DOE's energy hubs, this would comprise 15 or more centres looking to cut the energy, time and materials required to make things. The goal is to help US industries to compete with lowcost factories in emerging nations such as China, and to make it easier for start-up companies - including many renewable-energy firms - to bring new products to market. Congress has not yet acted on this proposal, but the administration has established several centres using existing funds from the DOE and other agencies.

Such efforts need to be supported and encouraged - especially by Congress, which holds the federal purse strings, and by the energy industry, which can tap vast amounts of cash for activities it perceives to be in its interest. And even here there is reason for optimism. Despite the ideological warfare that has riven Washington DC in recent years, both parties have generally endorsed the DOE's reform efforts. And industry leaders seem ready to work closely with researchers to bring innovative products to market. One example is the Clean Energy Trust, a Chicago-based consortium of energy companies that supports renewable-energy start-ups.

Congress and the Obama administration could greatly help this movement by reviving the idea of the Clean Energy Deployment Administration: a 'green bank' that would pool public and private money for large-scale investments in clean-energy infrastructure. The idea was proposed a few years ago, but abandoned amid budget wrangles. Now that the federal deficit is easing and the economy has begun to improve, it could find renewed support on both sides of the aisle. The future, for once, is starting to look brighter.

\section{Integrity mentors} Policies in Ireland and China make Nature's 2014 mentoring awards timely.

\section{$\mathrm{L}$} ast month the Chinese Academy of Sciences issued a powerfully worded statement Towards Excellence in Science (go.nature.com/pnhi9k). In encouraging a scientific culture of challenging the status quo, it includes a passage that speaks to laboratory behaviour: "To achieve scientific excellence, the scientific community needs to consciously advocate and uphold the scientific spirit, promote the value and focus of science in seeking truth and innovation, establish management structures and mechanisms that suit the characteristics and rules of scientific research, and discourage scientific behaviour aimed only at short-term success or individual benefits."

This week, the Irish Universities Association has issued a Concordat on research integrity, which includes mention of two aspects (among several) of scientific behaviour needing support: "reliability in performing research (meticulous, careful and attentive to detail), and in communication of the results (fair and full and unbiased reporting), and objectivity: interpretations and conclusions must be founded on facts and data capable of proof and secondary review; there should be transparency in the collection, analysis and interpretation of data, and verifiability of the scientific reasoning."

Such statements could all too easily be ignored unless they have teeth. In that spirit, readers might do well to focus on a clause in a document produced by Science Foundation Ireland (SFI), the country's main funding agency and a collaborator on the integrity Concordat. On page 32 of its strategic plan, Agenda 2020, is the statement that research integrity will be scrutinized by external audits (go.nature.com/xjudiz). Congratulations to the SFI for showing more determination than most to back words with actions.

Excellent science requires, not least, a capacity for researchers to be ruthlessly self-critical — in other words, assuring technical integrity. On discovering something interesting, they need to assume at the outset that they are deluded - that the combination of their object of study and their experimental, or theoretical or simulation set-up is conspiring to make them mistakenly believe that they have a startling new insight to offer an admiring world. They need to show their analyses or data to trusted but critically minded colleagues, in order to avoid mistakes and cherry-picking. Such a culture is best bred by tough but supportive laboratory mentors. In its annual mentoring awards, which has been held since 2005, Nature has rewarded outstanding mentors in many countries and regions.

Given Ireland's evident determination to sustain best practices, it $\rightarrow$ NATURE.COM To comment online, click on Editorials at: go.nature.com/xhunqu is timely that this year's mentoring competition is for scientists resident in that country and in Northern Ireland. Candidates need to be nominated by past mentees using forms available at go.nature.com/hmezau. Deadline: 4 August. 